\title{
Abdominal CT: a radiologist-driven adjustment of the dose of iodinated contrast agent approaches a calculation per lean body weight
}

\author{
Moreno Zanardo ${ }^{1 *}\left(\mathbb{D}\right.$, Fabio Martino Doniselli ${ }^{2}$, Anastassia Esseridou ${ }^{3}$, Stefania Tritella ${ }^{3}$, Chiara Mattiuz ${ }^{3}$, \\ Laura Menicagli ${ }^{3}$, Giovanni Di Leo ${ }^{3}$ and Francesco Sardanelli, ${ }^{3,4}$
}

\begin{abstract}
Background: The contrast agent (CA) dose for abdominal computed tomography (CT) is typically based on patient total body weight (TBW), ignoring adipose tissue distribution. We report on our experience of dosing according to the lean body weight (LBW).

Methods: After Ethics Committee approval, we retrospectively screened 219 consecutive patients, 18 being excluded for not matching the inclusion criteria. Thus, 201 were analysed (106 males), all undergoing a contrastenhanced abdominal CT with iopamidol $(370 \mathrm{mgl} / \mathrm{mL})$ or iomeprol $(400 \mathrm{mgl} / \mathrm{mL})$. LBW was estimated using validated formulas. Liver contrast-enhancement $\left(C E_{L}\right)$ was measured. Data were reported as mean \pm standard deviation. Pearson correlation coefficient, ANOVA, and the Levene test were used.

Results: Mean age was $66 \pm 13$ years, TBW $72 \pm 15 \mathrm{~kg}$, LBW $53 \pm 11 \mathrm{~kg}$, and LBW/TBW ratio $74 \pm 8 \%$; body mass index was $26 \pm 5 \mathrm{~kg} / \mathrm{m}^{2}$, with 9 underweight patients (4\%), 82 normal weight (41\%), 76 overweight (38\%), and 34 obese (17\%). The administered CA dose was $0.46 \pm 0.06 \mathrm{gl} / \mathrm{kg}$ of TBW, corresponding to $0.63 \pm 0.09 \mathrm{gl} / \mathrm{kg}$ of LBW. A negative correlation was found between TBW and CA dose $(r=-0.683, p<0.001)$. CE $\mathrm{L}_{\mathrm{L}}$ (Hounsfield units) was $51 \pm 18$ in underweight patients, $44 \pm 8$ in normal weight, $42 \pm 9$ in overweight, and $40 \pm 6$ in obese, with a significant difference for both mean $(p=0.004)$ and variance $(p<0.001)$. A low but significant positive correlation was found between $C_{L}$ and CA dose in $g$ l per TBW $(r=0.371, p<0.001)$ or per LBW $(r=0.333, p<0.001)$.

Conclusions: The injected CA dose was highly variable, with obese patients receiving a lower dose than underweight patients, as a radiologist-driven 'compensation effect'. Diagnostic abdomen $\mathrm{CT}$ examinations may be obtained using $0.63 \mathrm{gl} / \mathrm{kg}$ of LBW.
\end{abstract}

Keywords: Abdomen, Body composition, Body weight, Contrast media, Tomography (x-ray, computed)

\section{Key points}

- Contrast agent dose based on total body weight ignores body composition

- Underweight patients received a higher dose than obese patients

\footnotetext{
* Correspondence: moreno.zanardo@unimi.it

${ }^{1} \mathrm{PhD}$ Course in Integrative Biomedical Research, Department of Biomedical Sciences for Health, Università degli Studi di Milano, Via Mangiagalli 31, 20133 Milan, Italy

Full list of author information is available at the end of the article
}

- Diagnostic abdominal CT examinations may be obtained using $0.63 \mathrm{gI} / \mathrm{kg}$ of lean body weight

\section{Background}

Factors impacting on contrast enhancement in single-energy computed tomography (CT) include concentration and dose of the iodinated contrast agent (CA), injection rate, scanning delay time, saline-solution flushing, and cardiac output [1-3]. The CA dose, expressed in $\mathrm{gI} / \mathrm{kg}$, is one of the most important factors determining the parenchymal liver contrast enhancement $\left(\mathrm{CE}_{\mathrm{L}}\right)[4]$. 
When considering delayed scanning phases, another important factor determining $\mathrm{CE}_{\mathrm{L}}$ is the $\mathrm{CA}$ biodistribution into the intra- and extra-vascular spaces, which are both related to the body size $[5,6]$. As a consequence, if a fixed amount of iodine is administered to patients, which is still a usual practice [7], some may receive an unnecessary high dose while others may receive a suboptimal dose.

Since 2000, several studies have demonstrated smaller variations in $\mathrm{CE}_{\mathrm{L}}$ when $\mathrm{CA}$ is dosed on the patient total body weight (TBW) instead of administering a fixed amount [8-14]. Dosing according to TBW is reasonably effective, but it can lead to overdosing obese patients or underdosing patients with high contribution of the lean body weight (LBW) over the TBW, such as athletes. Indeed, a large proportion of TBW of obese patients consists of poorly perfused adipose tissue, where the CA poorly distributes $[2,10,15,16]$, as $99 \%$ of metabolic processes take place in the LBW $[17,18]$.

Various body size indexes have been proposed to determine the CA dose for abdominal multiphasic or portal-venous-phase CT, demonstrating better results for LBW rather than TBW [16, 19-27]. LBW can be determined by many different methods such as dual-energy $\mathrm{x}$-ray absorptiometry, CT, ultrasound, and bioelectrical impedance analysis [28], although an equation based on the patient TBW, height, and gender, or the determination by bioelectrical impedance balance is the most suitable for calculation [18].

Previous studies using LBW for CA dose calculation mainly compared different strategies and, to our knowledge, no study has performed an optimisation process to find out what is the minimal diagnostic CA dose based on the LBW [19-27]. Moreover, authors limited their studies mainly to normal-weight or overweight populations. In our opinion, advantages of CA dose calculation based on the LBW instead of the TBW may appear mostly in underweight and obese patients.

The aim of this preliminary retrospective study was to report on our experience on multiphasic abdominal CT and to calculate the LBW-derived CA dose that was equivalent to that derived from TBW, leading to the same amount of injected iodine. In other words, our final aim was to find a feasible formula to standardise the amount of $\mathrm{CE}_{\mathrm{L}}$ across patients of all sizes, whereas the amount of iodine delivered will vary by patient size and by whether LBW or TBW is used to determine the total amount of injected iodine.

\section{Methods}

\section{Study design and population}

This retrospective cross-sectional study was approved by the local Ethics Committee (San Raffaele Hospital, Milan, authorisation number 160/int/2016). A series of consecutive patients who underwent a contrast-enhanced multiphasic abdominal CT or portal-venous-phase CT at our institution from June to September 2016 were reviewed.

Exclusion criteria were: history of chronic liver disease (cirrhosis, local or diffuse liver fatty infiltration, or glycogen storage disease); congestive heart failure; prior cardiac valve replacement; restrictive and/or constrictive pericarditis; implanted devices (pacemakers, defibrillators, insulin pumps). Although Hamer et al. [29] defined steatotic hepatitis when liver parenchyma has an average $\mathrm{CT}$ value on unenhanced images lower than 40 Hounsfield units (HU), we excluded patients with $\mathrm{CT}$ values below $30 \mathrm{HU}$ in the unenhanced scan. As a consequence, low grades of steatosis have presumably been included in our study population.

\section{CT protocol}

All patients were studied using a 64-row CT scan (Somatom Definition, Siemens Medical Solution, Erlangen, Germany) with $120 \mathrm{kVp}$, tube load from 100 to $200 \mathrm{mAs}$ depending on automatic exposure control system (CARE Dose 4D, Siemens Medical Solution, Erlangen, Germany), rotation time $0.5 \mathrm{~s}$, pitch 1, B30f medium smooth for kernel reconstruction technique and abdomen window.

Patients' TBW and height were registered in an electronic database. Moreover, a radiologist-driven dose of iopamidol (190 patients over 201) (Iopamiro 370; 370 $\mathrm{mgI} / \mathrm{mL}$; Bracco Imaging, Milan, Italy) or iomeprol (11 patients over 201) (Iomeron 400; $400 \mathrm{mgI} / \mathrm{mL}$; Bracco Imaging, Milan, Italy) was administered. While iopamidol is the main choice in our hospital for routine abdomen and chest CT, iomeprol is used for cardiac CT. Due to practical reasons (storage lack of iopamidol, the necessity of employing an already-open CA bottle, examination acquired during a cardiac session), some patients received iomeprol. A total of eight radiologists were responsible for the examinations. The general rule established in the department for the CA dose to be administered for multiphasic abdominal CT was to use doses proportional to the TBW, multiplying the patient body weight by a constant, which varied from 1.1 to $1.3 \mathrm{~mL} / \mathrm{kg}$, with adjustments when the CA dose was considered too high. Radiologists usually adopted their own spontaneous threshold, without any agreement among them. Another heuristic rule used by some professionals was 'patient weight in millilitres plus 10 additional millilitres of CA'.

The CA was administered intravenously through a 20-gauge needle using an automatic power injector (EmpowerCTA ${ }^{\circ}$ Contrast Injection System, Bracco Imaging, Milan, Italy) at the rate of $3 \mathrm{~mL} / \mathrm{s}$, followed by $50 \mathrm{~mL}$ of saline solution at the same rate. 
The scan delay was determined using an automated triggering hardware and a dedicated software (Bolus Tracking, Siemens Medical Solution, Erlangen, Germany). Specifically, low-dose monitor images were obtained in a single axial slice of the aorta after CA injection. When the descending aorta enhanced more than $100 \mathrm{HU}$, diagnostic scans of the abdomen were acquired after an additional delay of about $18 \mathrm{~s}$ (arterial phase), $30 \mathrm{~s}$ after arterial phase (portal-venous phase), and, only in specific cases, $90 \mathrm{~s}$ (nephrogenic phase). For the aim of this study, we considered only the portal venous phase.

\section{LBW estimation and image analysis}

According to the international classification of body mass index (BMI) from the WHO [30], patients were considered underweight when the BMI was lower than $18.5 \mathrm{~kg} / \mathrm{m}^{2}$, normal weight when between $18.5 \mathrm{~kg} / \mathrm{m}^{2}$ and $25 \mathrm{~kg} / \mathrm{m}^{2}$, overweight when between $25 \mathrm{~kg} / \mathrm{m}^{2}$ and $30 \mathrm{~kg} / \mathrm{m}^{2}$, and obese when higher than $30 \mathrm{~kg} / \mathrm{m}^{2}$.

According to Awai and colleagues [31] and Nyman [32], LBW was calculated using the James formula [33] (Eq. 1) or the Boer formula [33] (Eq. 2), due to better adherence of non-obese patients to the first and of obese patients to the latter:

$$
L B W_{\text {James }}=\left\{\begin{array}{c}
1.1 \times \text { weight }(\mathrm{kg})-128 \times\left(\frac{\text { weight }(\mathrm{kg})}{\text { height }(\mathrm{m})}\right)^{2} \text { men } \\
1.07 \times \text { weight }(\mathrm{kg})-148 \times\left(\frac{\text { weight }(\mathrm{kg})}{\text { height }(\mathrm{m})}\right)^{2} \text { women }
\end{array}\right\}
$$

$$
L B W_{\text {Boer }}=\left\{\begin{array}{c}
0.407 \times \text { weight }(\mathrm{kg})+0.267 \times \text { height }-19.2 \text { men } \\
0.252 \times \text { weight }(\mathrm{kg})+0.473 \times \text { height }-48.3 \text { women }
\end{array}\right\}
$$

All images were reviewed by a radiology resident with 2 years of experience in the field of abdominal CT. Attenuation measurements were obtained by manually placing a rounded region of interest in the anterior (III or IVb Couinaud) and in the posterior (VI Couinaud) segments at the level of the main portal vein with a diameter of between 2 and $3 \mathrm{~cm}$; these two values were averaged. Two different regions in anterior and posterior liver parenchyma were chosen because of subtle territorial differences in liver enhancement, probably due to different levels of fatty infiltration and vascularity. Focal hepatic lesions, blood vessels, bile ducts, calcifications, as well as artefacts, if present, were carefully avoided.

\section{Statistical analysis}

For each patient, we retrieved from the radiological report the amount and type of injected CA in millilitres and the dose was calculated both per TBW and LBW. Moreover, to account for the different concentration of iodine of the two used CAs, we converted the absolute injected amount from millilitres to grams of iodine (gI).

The $\mathrm{CE}_{\mathrm{L}}$ was calculated as the difference between the $\mathrm{CT}$ value measured in the portal venous phase and that measured before CA injection. To this aim, regions of interest were copy-pasted from one phase to another.

The distribution of $\mathrm{CE}_{\mathrm{L}}$ was calculated for the whole population and for the four subgroups of BMI. Bivariate correlation analysis was performed using the Pearson correlation coefficient. The comparison of the mean CA dose, as well as of the mean $\mathrm{CE}_{\mathrm{L}}$ among the four subgroups of BMI was performed using the one-way analysis of variance (ANOVA); the variance of $\mathrm{CE}_{\mathrm{L}}$ was compared using the Levene test of homoscedasticity.

Differences in the practice of CA dose calculation among radiologists were evaluated using the ANOVA.

Continuous data were presented as mean and standard deviation while categorical data were presented as counts and percentages. The coefficient of variation $(\mathrm{CoV})$ was calculated as the standard deviation/mean ratio.

Statistical analysis was carried out using SPSS Statistics (SPSS v.24, IBM Inc., Armonk, NY, USA). A $p$ value < 0.050 was regarded as statistically significant.

\section{Results}

\section{Distributions}

A total of 219 patients were screened, 18 of whom were excluded for having chronic liver disease $(n=13)$, implanted device $(n=4)$, or congestive heart failure $(n=1)$. Thus, 201 patients were analysed, 106 men (53\%) and 95 women (47\%), with a mean age of $66 \pm 13$ years (CoV 20\%), mean TBW $72 \pm 15 \mathrm{~kg}$ (CoV 21\%), mean LBW $53 \pm 11 \mathrm{~kg}$ (CoV $20 \%)$, and mean LBW/TBW $74 \pm 8 \%$ (CoV $11 \%)$.

The mean BMI was $26 \pm 5 \mathrm{~kg} / \mathrm{m}^{2}$ with 9 patients (4\%) classified as underweight, $82(41 \%)$ as normal weight, 76 (38\%) as overweight and 34 (17\%) as obese. Demographics and other data of the study population are presented in Table 1.

The mean injected amount of CA was $32 \pm 5 \mathrm{gI}(\mathrm{CoV}$ $16 \%)$. Expressed in terms of $\mathrm{gI} / \mathrm{kg}$ of TBW or LBW, the mean CA dose was $0.46 \pm 0.06(\mathrm{CoV} 13 \%)$ or $0.63 \pm 0.09$ (CoV 14\%), respectively.

The mean $\mathrm{CT}$ value of the liver was $53 \pm 8 \mathrm{HU}$ before CA injection and $96 \pm 13 \mathrm{HU}$ in the portal venous phase, for a mean $\mathrm{CE}_{\mathrm{L}}$ of $43 \pm 9 \mathrm{HU}(\mathrm{CoV} 21 \%)$. These and other data are reported in Table 2.

\section{Correlation analysis}

A significant high negative correlation was observed between CA dose and TBW $(r=-0.683 ; p<0.001)$. In particular, the mean CA dose was $0.56 \pm 0.08 \mathrm{gI} / \mathrm{kg}$ for underweight, $0.48 \pm 0.05 \mathrm{gI} / \mathrm{kg}$ for normal-weight patients, $0.44 \pm 0.04 \mathrm{gI} / \mathrm{kg}$ for overweight patients, and $0.41 \pm 0.05 \mathrm{gI} / \mathrm{kg}$ for obese patients $(p<0.001)$ (Fig. 1$)$. 
Table 1 Demographic characteristics of 201 patients of the study population

\begin{tabular}{ll}
\hline Item & Value \\
\hline Total number of patients & 201 \\
Gender & 106 males (53\%) \\
Mean age (years) & $66 \pm 13$ \\
Mean height $(\mathrm{m})$ & $1.66 \pm 0.10$ \\
Mean TBW $(\mathrm{kg})$ & $72 \pm 15$ \\
Mean LBW $(\mathrm{kg})$ & $53 \pm 11$ \\
Mean percent $\mathrm{LBW} / \mathrm{TBW}(\%)$ & $74 \pm 8$ \\
Mean BMI $\left(\mathrm{kg} / \mathrm{m}^{2}\right):$ & $26 \pm 5$ \\
Underweight $\left(\mathrm{BMI}<18.5 \mathrm{~kg} / \mathrm{m}^{2}\right)$ & $9(4 \%)$ \\
Normal weight $\left(18.5 \leq \mathrm{BMI}<25 \mathrm{~kg} / \mathrm{m}^{2}\right)$ & $82(41 \%)$ \\
Overweight $\left(25 \leq \mathrm{BMI}<30 \mathrm{~kg} / \mathrm{m}^{2}\right)$ & $76(38 \%)$ \\
Obese $\left(\mathrm{BMI} \geq 30 \mathrm{~kg} / \mathrm{m}^{2}\right)$ & $34(17 \%)$ \\
\hline
\end{tabular}

$B M I$ body mass index, $L B W$ lean bodyweight, $T B W$ total bodyweight

Table 2 Mean contrast agent dose administered in 201 patients of the study population

\begin{tabular}{lll}
\hline Item & Value $^{\mathrm{a}}$ & CoV \\
\hline Amount of injected CA $(\mathrm{g})$ & $32 \pm 5$ & $16 \%$ \\
Dose of CA per TBW $(\mathrm{gl} / \mathrm{kg})$ & $0.46 \pm 0.06$ & $13 \%$ \\
Dose of CA per TBW $(\mathrm{gl} / \mathrm{kg})$ according to BMl & & \\
Underweight $\left(\mathrm{BMl}<18.5 \mathrm{~kg} / \mathrm{m}^{2}\right)$ & $0.56 \pm 0.08$ & $14 \%$ \\
Normal weight $\left(18.5 \leq \mathrm{BMl}<25 \mathrm{~kg} / \mathrm{m}^{2}\right)$ & $0.48 \pm 0.05$ & $10 \%$ \\
Overweight $\left(25 \leq \mathrm{BMl}<30 \mathrm{~kg} / \mathrm{m}^{2}\right)$ & $0.44 \pm 0.04$ & $9 \%$ \\
Obese $\left(\mathrm{BMI} \geq 30 \mathrm{~kg} / \mathrm{m}^{2}\right)$ & $0.41 \pm 0.04$ & $10 \%$ \\
Dose of CA per $\mathrm{LBW}(\mathrm{gl} / \mathrm{kg})$ & $0.63 \pm 0.09$ & $14 \%$ \\
Dose of CA per $\mathrm{LBW}(\mathrm{gl} / \mathrm{kg}) \mathrm{according}$ to BMl & & \\
Underweight $\left(\mathrm{BMl}<18.5 \mathrm{~kg} / \mathrm{m}^{2}\right)$ & $0.68 \pm 0.11$ & $16 \%$ \\
Normal weight $\left(18.5 \leq \mathrm{BMl}<25 \mathrm{~kg} / \mathrm{m}^{2}\right)$ & $0.62 \pm 0.08$ & $13 \%$ \\
Overweight $\left(25 \leq \mathrm{BMl}<30 \mathrm{~kg} / \mathrm{m}^{2}\right)$ & $0.62 \pm 0.08$ & $13 \%$ \\
Obese $\left(\mathrm{BMI} \geq 30 \mathrm{~kg} / \mathrm{m}^{2}\right)$ & $0.65 \pm 0.11$ & $17 \%$ \\
Liver contrast enhancement $(\mathrm{HU})^{\mathrm{d}}$ & $43 \pm 9$ & $21 \%$ \\
Liver contrast enhancement $(\mathrm{HU})$ according to BMl & \\
Underweight $\left(\mathrm{BMl}<18.5 \mathrm{~kg} / \mathrm{m}^{2}\right)$ & $51 \pm 18$ & $35 \%$ \\
Normal weight $\left(18.5 \leq \mathrm{BMl}<25 \mathrm{~kg} / \mathrm{m}^{2}\right)$ & $44 \pm 8$ & $18 \%$ \\
Overweight $\left(25 \leq \mathrm{BMl}<30 \mathrm{~kg} / \mathrm{m}^{2}\right)$ & $42 \pm 9$ & $18 \%$ \\
Obese $\left(\mathrm{BMI} \geq 30 \mathrm{~kg} / \mathrm{m}^{2}\right)$ & $40 \pm 6$ & $15 \%$ \\
\hline
\end{tabular}

${ }^{\mathrm{a}}$ Data represent mean \pm standard deviation

${ }^{\mathrm{b}}$ This trend showed a significant negative association $(p<0.001)$

${ }^{c}$ The comparison was not statistically significant $(p \geq 0.065)$

${ }^{d}$ Calculated as the difference between the computed tomography (CT) value measured in the venous phase and that measured before contrast agent injection

${ }^{\mathrm{e}}$ This trend showed a significant negative association $(p=0.004)$ $B M I$ body mass index, $C A$ contrast agent, CoV coefficient of variation, $g /$ grams of iodine, HU Hounsfield units, LBW lean bodyweight, TBW total bodyweight
A low but significant negative correlation was found between $\mathrm{CE}_{\mathrm{L}}$ and TBW $(r=-0.292 ; p<0.001)$ or LBW $(r=-0.316 ; p<0.001)$. A low but significant positive correlation was found between $\mathrm{CE}_{\mathrm{L}}$ and $\mathrm{CA}$ dose in $\mathrm{gI} / \mathrm{kg}$ of TBW $(r=0.371, p<0.001)$ or in $\mathrm{gI} / \mathrm{kg}$ of LBW $(r=0.333, p<0.001)$.

A low but significant negative correlation was found between $\mathrm{CE}_{\mathrm{L}}$ and $\mathrm{BMI}(r=-0.206 ; p=0.003)$. According to the four subgroups of $\mathrm{BMI}$, the mean $\mathrm{CE}_{\mathrm{L}}$ was $51 \pm$ $18 \mathrm{HU}(\mathrm{CoV} 35 \%)$ in underweight patients, $44 \pm 8 \mathrm{HU}$ (CoV 18\%) in normal-weight patients, $42 \pm 9 \mathrm{HU}(\mathrm{CoV}$ $18 \%)$ in overweight patients, and $40 \pm 6 \mathrm{HU}(\mathrm{CoV} 15 \%)$ in obese patients with a statistically significant difference of both the mean $(p=0.004)$ and variance $(p<0.001)$.

The mean CA dose in $\mathrm{gI} / \mathrm{kg}$ of TBW did not differ significantly among the eight radiologists, varying from 0.43 to $0.47 \mathrm{gI} / \mathrm{kg}(p=0.510)$.

\section{Discussion}

In this study, we retrospectively evaluated 201 patients undergoing an abdominal CT at our institution. The main finding was the evidence of a kind of 'compensation effect,' subjectively operated by the radiologists, on the injected CA dose, always considering its calculation in terms of $\mathrm{gI} / \mathrm{kg}$. In fact, we observed a deviation from proportionality between the TBW and the injected CA dose that they declared when questioned about how they decide CA dose. This was clear in particular for obese patients, which received a CA dose lower than that theoretically based on the TBW. Indeed, a high negative correlation was found between the patient TBW and the administered CA dose, meaning that the higher the TBW, the lower the CA dose.

Although there are no recommendations for obese patients (apart from a general limit of $250 \mathrm{~mL}$ reported on the drug information sheet), radiologists preferred to apply a kind of precautionary principle by subjectively reducing CA dose in obese patients. We could speculate that radiologists have somehow weighted the CA dose according to a plausible LBW, even without being aware of the exact LBW.

Importantly, although the CA dose was reduced in obese patients, all CT examinations were judged as diagnostic and no patients received a repeat examination. This allows us to hypothesise a margin for dose reduction, especially in underweight patients, who in our study received a dose in $\mathrm{gI} / \mathrm{kg}$ significantly higher than obese ones. In fact, the other side of the above-mentioned compensation effect is a potential overdosing in underweight patients, partially due to the fear of a non-diagnostic examination if injected strictly according to the TBW.

Another result of this study is a trend toward a lower and lower variability of $\mathrm{CE}_{\mathrm{L}}$ from underweight to obese patients (Levene test $p<0.001$ ). We speculate that this evidence indirectly demonstrates that LBW could be 


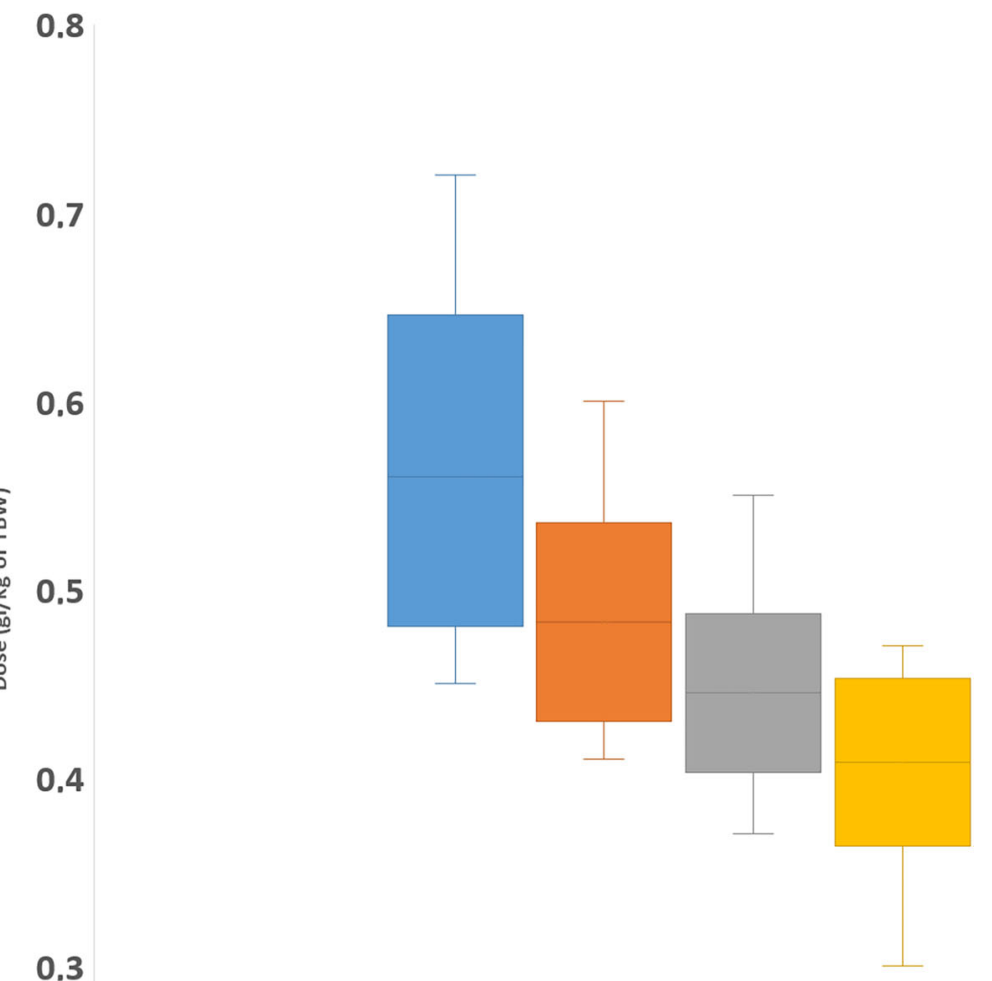

0.2

$\square$ Underweight $\square$ Normal weight $\square$ Overweight $\square$ Obese

Fig. 1 Box plot showing the mean CA dose (in grams of iodine per kilogram of total body weight) per each of the 4 subgroups of the body mass index (BMI) according the WHO (centre line). Mean \pm standard deviation (box) and the minimum and the maximum values are also showed (outer lines)

better suited for dosing CA than TBW. In fact, poor but non-negligible CA perfusion in the adipose tissue would only increase variability of $\mathrm{CE}_{\mathrm{L}}$.

Interestingly, the practice of adjusting the CA dose, unconsciously weighting for the LBW, was observed in all the staff radiologists, without significant differences among them. Of note, this shared practice spontaneously evolved in the department real-life. In addition, repeat CT examinations due to insufficient parenchymal contrast-enhancement has never been reported.

We also obtained an equivalent CA dose, i.e. the CA dose based on the LBW that would have provided the same amount of iodine that was actually administered. In the study population, a mean of $32 \pm 5$ gI was injected, corresponding to $0.46 \pm 0.06 \mathrm{gI} / \mathrm{kg}$ of TBW or $0.63 \pm 0.09 \mathrm{gI} / \mathrm{kg}$ of LBW. Although the latter data were back calculated from the raw data, it is reasonably to think that if $0.63 \mathrm{gI} / \mathrm{kg}$ of LBW had been used instead of $0.46 \mathrm{gI} / \mathrm{kg}$ of TBW, it would have resulted in an equivalent mean $\mathrm{CE}_{\mathrm{L}}$.
The use of LBW instead of TBW on a patient-by-patient base could impact on the overall CA dose to the population, permitting a more personalised approach to CA administration and a possible reduction of the total amount of CA administered to the population. Moreover, as obesity increases the risk for kidney disease [34], a reduction of the overall dose to obese patients represents a further advantage in terms of risk of nephrotoxic effects from iodinated CA. The associated cost reduction, dependent on changes in administered volume, is another advantage potentially deriving from this approach [7]. However, although Awai et al. [31] have already identified LBW as the best indicator for determining the proper amount of CA, its use has never entered clinical practice.

When optimising CA dose, several factors should be taken into account [35]. From pharmacokinetics, it is known that drug distribution in the arterial phase mainly depends on heart function, while in the portal venous phase vasoconstriction-vasodilatation play the main role in determining CA distribution $[18,36]$. We based our 
results on $\mathrm{CE}_{\mathrm{L}}$ but a wide variety of para-physiological conditions can affect liver parenchyma in the general population (e.g. steatotic hepatitis, diffuse cirrhosis, previous liver diseases) that can affect $\mathrm{CE}_{\mathrm{L}}$.

This study has limitations. First of all, its retrospective design and relatively small number of patients, which implies an uneven distribution of patient weights. In addition, we estimated the patient LBW using the James or Boer formulas. Indeed, LBW determined with the aid of a total body composition analyser may yield a more accurate analysis. There are several prediction formulas for LBW [33, 37-39] that may yield different results. However, for the aim of our study, the formulas we used are considered the simplest methods for retrospective calculation of the LBW, confirmed by Caruso et al. [40].

In conclusion, the CA dose injected at our institution for abdominal multiphasic $\mathrm{CT}$ was highly variable, with obese patients receiving a much lower dose than underweight patients, as a radiologist-driven 'compensation effect'. Diagnostic abdominal CT may be obtained using $0.63 \mathrm{gI} / \mathrm{kg}$ of LBW and margins for dose reduction do exist.

\section{Abbreviations}

BMI: Body mass index; CA: Contrast agent; $\mathrm{CE}_{\mathrm{L}}$ : Liver contrast enhancement; CoV: Coefficient of variation; CT: Computed tomography; HU: Hounsfield units; LBW: Lean body weight; TBW: Total body weight

\section{Availability of data and materials}

Original anonymised individual data are available on reasonable request sent to the corresponding author.

\section{Funding}

This study was supported by local research funds of the IRCCS Policlinico San Donato, a clinical research hospital partially funded by the Italian Ministry of Health.

\section{Authors' contributions}

$M Z$, FMD, GDL, and FS contributed in the study design. AE, ST, CM, and LM performed clinical examinations. MZ, FMD, and GDL performed statistical analysis. All authors drafted the manuscript. All authors gave intellectual contribution to the article content. All authors revised and approved the manuscript.

\section{Ethics approval and consent to participate}

This retrospective study was approved by the Ethics Committee of San Raffaele Hospital, Milan and patients' consent was waived (protocol code 160/int/2016).

\section{Consent for publication}

No individual data or images are presented in this article.

\section{Competing interests}

Francesco Sardanelli is the Editor-in-Chief of European Radiology Experimental. For this reason, he was not involved in any ways in the revision/decision process regarding this article, which was completely managed by the Deputy Editor, Dr. Akos Varga-Szemes (Medical University of South Carolina, SC, USA). In addition, Francesco Sardanelli declares to have received grants from, or being a member of, Speakers' Bureau/Advisory Board for Bayer, Bracco, and General Electric.

\section{Publisher's Note}

Springer Nature remains neutral with regard to jurisdictional claims in published maps and institutional affiliations.

\section{Author details}

${ }^{1} \mathrm{PhD}$ Course in Integrative Biomedical Research, Department of Biomedical Sciences for Health, Università degli Studi di Milano, Via Mangiagalli 31, 20133 Milan, Italy. ${ }^{2}$ Postgraduate School in Radiodiagnostics, Università degli Studi di Milano, Via Festa del Perdono 7, 20122 Milan, Italy. ${ }^{3}$ Radiology Unit, IRCCS Policlinico San Donato, Via Morandi 30, 20097 San Donato Milanese, Italy. ${ }^{4}$ Department of Biomedical Sciences for Health, Università degli Studi di Milano, Via Morandi 30, 20097 San Donato Milanese, Italy.

Received: 19 August 2018 Accepted: 19 October 2018

Published online: 05 December 2018

\section{References}

1. Chambers TP, Baron RL, Lush RM (1994) Hepatic CT enhancement. Part I. Alterations in the volume of contrast material within the same patients. Radiology 193:513-517

2. Bae KT, Heiken JP, Brink JA (1998) Aortic and hepatic peak enhancement at CT: effect of contrast medium injection rate-pharmacokinetic analysis and experimental porcine model. Radiology 206:455-464

3. Kim T, Murakami T, Takahashi $S$ et al (1998) Effects of injection rates of contrast material on arterial phase hepatic CT. AJR Am J Roentgenol 171: 429-432

4. Heiken JP, Brink JA, McClennan BL et al (1995) Dynamic incremental CT: effect of volume and concentration of contrast material and patient weight on hepatic enhancement. Radiology 195:353-357

5. Kormano M, Dean PB (1976) Extravascular contrast material: the major component of contrast enhancement. Radiology 121:379-382

6. Kormano M, Partanen K, Soimakallio S, Kivimäki T (1983) Dynamic contrast enhancement of the upper abdomen: effect of contrast medium and body weight. Invest Radiol 18:364-367

7. Davenport MS, Parikh KR, Mayo-Smith WW, Israel GM, Brown RK, Ellis JH (2017) Effect of fixed-volume and weight-based dosing regimens on the cost and volume of administered iodinated contrast material at abdominal CT. J Am Coll Radiol 14:359-370

8. Yamashita Y, Komohara Y, Takahashi M et al (2000) Abdominal helical CT: evaluation of optimal doses of intravenous contrast material-a prospective randomized study. Radiology 216:718-723

9. Awai K, Inoue M, Yagyu Y et al (2004) Moderate versus high concentration of contrast material for aortic and hepatic enhancement and tumor-to-liver contrast at multi-detector row CT. Radiology 233:682-688

10. Awai K, Hiraishi K, Hori S (2004) Effect of contrast material injection duration and rate on aortic peak time and peak enhancement at dynamic CT involving injection protocol with dose tailored to patient weight. Radiology 230:142-150

11. Awai K, Hori S (2003) Effect of contrast injection protocol with dose tailored to patient weight and fixed injection duration on aortic and hepatic enhancement at multidetector-row helical CT. Eur Radiol 13:2155-2160

12. Yanaga Y, Awai K, Nakayama Y et al (2007) Pancreas: patient body weight tailored contrast material injection protocol versus fixed dose protocol at dynamic CT. Radiology 245:475-482

13. Ichikawa T, Erturk SM, Araki T (2006) Multiphasic contrast-enhanced multidetector-row $C T$ of liver: contrast-enhancement theory and practical scan protocol with a combination of fixed injection duration and patients' body-weight-tailored dose of contrast material. Eur J Radiol 58:165-176

14. Arana E, Martí-Bonmatí L, Tobarra E, Sierra C (2009) Cost reduction in abdominal CT by weight-adjusted dose. Eur J Radiol 70:507-511

15. Bae KT, Heiken JP, Brink JA (1998) Aortic and hepatic contrast medium enhancement at CT. Part I. Prediction with a computer model. Radiology 207:647-655

16. Kondo H, Kanematsu M, Goshima S et al (2008) Abdominal multidetector $\mathrm{CT}$ in patients with varying body fat percentages: estimation of optimal contrast material dose. Radiology 249:872-877

17. Roubenoff R, Kehayias JJ (1991) The meaning and measurement of lean body mass. Nutr Rev 49:163-175

18. Morgan DJ, Bray KM (1994) Lean body mass as a predictor of drug dosage. Implications for drug therapy. Clin Pharmacokinet 26:292-307

19. Ho LM, Nelson RC, Delong DM (2007) Determining contrast medium dose and rate on basis of lean body weight: does this strategy improve patientto-patient uniformity of hepatic enhancement during multi-detector row CT? Radiology 243:431-437 
20. Bae KT, Seeck BA, Hildebolt CF et al (2008) Contrast enhancement in cardiovascular MDCT: effect of body weight, height, body surface area, body mass index, and obesity. AJR Am J Roentgenol 190:777-784

21. Yanaga $Y$, Awai $K$, Nakaura T et al (2009) Effect of contrast injection protocols with dose adjusted to the estimated lean patient body weight on aortic enhancement at CT angiography. 192:1071-1078

22. Kondo H, Kanematsu M, Goshima S et al (2010) Body size indexes for optimizing iodine dose for aortic and hepatic enhancement at multidetector CT: comparison of total body weight, lean body weight, and blood volume. Radiology 254:163-169

23. Kondo H, Kanematsu M, Goshima S et al (2011) Aortic and hepatic enhancement at multidetector CT: evaluation of optimal iodine dose determined by lean body weight. Eur J Radiol 80:e273-e277

24. Onishi H, Murakami T, Kim T et al (2011) Abdominal multi-detector row CT: effectiveness of determining contrast medium dose on basis of body surface area. Eur J Radiol 80:643-647

25. Svensson A, Nouhad J, Cederlund K et al (2012) Hepatic contrast medium enhancement at computed tomography and its correlation with various body size measures. Acta Radiol 53:601-606

26. Kidoh M, Nakaura T, Oda S et al (2013) Contrast enhancement during hepatic computed tomography: effect of total body weight, height, body mass index, blood volume, lean body weight, and body surface area. J Comput Assist Tomogr 37:159-164

27. Kondo H, Kanematsu M, Goshima S et al (2013) Body size indices to determine iodine mass with contrast-enhanced multi-detector computed tomography of the upper abdomen: does body surface area outperform total body weight or lean body weight? Eur Radiol 23:1855-1861

28. Prado CM, Heymsfield SB (2014) Lean tissue imaging: a new era for nutritional assessment and intervention. JPEN J Parenter Enteral Nutr 38: 940-953

29. Hamer OW, Aguirre DA, Casola G, Lavine JE, Woenckhaus M, Sirlin CB (2006) Fatty liver: imaging patterns and pitfalls. Radiographics 26:1637-1653

30. WHO (2016) Obesity and overweight. Available at: http://www.who.int/en/ news-room/fact-sheets/detail/obesity-and-overweight. Accessed 1 Aug 2018

31. Awai K, Kanematsu M, Kim T et al (2016) The optimal body size index with which to determine iodine dose for hepatic dynamic CT: a prospective multicenter study. Radiology 278:773-781

32. Nyman $U$ (2016) James lean body weight formula is not appropriate for determining $\mathrm{CT}$ contrast media dose in patients with high body mass index. Radiology 278:956-957

33. Waterlow JC, James WPT, for DHSS/MRC Group on Obesity Research (1976) Research on obesity: a report of the DHSS/MRC Group. Her Majesty's Stationary Office, London

34. Boer P (1984) Estimated lean body mass as an index for normalization of body fluid volumes in humans. Am J Physiol 247:F632-F636

35. Wang Y, Chen X, Song Y, Caballero B, Cheskin LJ (2008) Association between obesity and kidney disease: a systematic review and meta-analysis. Kidney Int 73:19-33

36. Bae KT (2010) Intravenous contrast medium administration and scan timing at CT: considerations and approaches. Radiology 256:32-61

37. Taylor HL, Brozek J, Keys A (1952) Basal cardiac function and body composition with special reference to obesity. J Clin Invest 31:976-983

38. Janmahasatian S, Duffull SB, Ash S, Ward LC, Byrne NM, Green B (2005) Quantification of lean bodyweight. Clin Pharmacokinet 44:1051-1065

39. Hume R (1966) Prediction of lean body mass from height and weight. J Clin Pathol 19:389-391

40. Caruso D, De Santis D, Rivosecchi F et al (2018) Lean body weight-tailored iodinated contrast injection in obese patient: Boer versus James formula. Biomed Res Int https://doi.org/10.1155/2018/8521893

\section{Submit your manuscript to a SpringerOpen ${ }^{\circ}$ journal and benefit from:}

- Convenient online submission

- Rigorous peer review

- Open access: articles freely available online

- High visibility within the field

- Retaining the copyright to your article

Submit your next manuscript at $\boldsymbol{\nabla}$ springeropen.com 